Closing the gates
Us visa rules tighten
controls on visiting
researchers
p349

\title{
Ecological riches threatened as oil-spill history repeats itself
}

Monica Salomone, Madrid

"It is as if we have not learned anything from the past," says Ramon Núñez, director of the Aquarium Finisterrae in La Coruña on Spain's northwestern coast. Núñez's aquarium, home to 35,000 fish and countless marine invertebrates, was established three years ago in response to an oil spill that hit the surrounding coastline in 1992. It is now the symbol of a new disaster.

The animals it houses cannot survive without the water flowing in through the sluice gates that connect the aquarium to the sea. But heavy fuel oil, washed ashore from the wreck of the tanker Prestige, is flowing through the gates and threatening the fish inside.

Núñez is waiting to see how much more oil will escape from the tanker, which sank 250 kilometres offshore on 19 November. Between 10,000 and 20,000 tonnes had found its way into the open ocean, contaminating 400 kilometres of coastline, as Nature went to press. Further slicks are expected to be washed ashore this week. "We are yet to see the worst of it," says Victoriano Urgorri, a marine zoologist at the University of Santiago de Compostela.

Some 60,000 tonnes of oil went down with the Prestige, which broke in two before sinking. Oceanographers estimate that the temperature on the sea floor, 3.6 kilometres below the surface, is $2-3^{\circ} \mathrm{C}$. The heavy oil on board the tanker freezes at $6{ }^{\circ} \mathrm{C}$ and so is unlikely to leak out. But planes flying over the site of the wreck last weekend reported that large new slicks have appeared where the vessel sank. The French government has sent the Nautile, a deep-water research submarine, to assess the situation.

The Spanish Society of Ornithology says that several hundred birds have already been treated for oil contamination. Almost 20 bird species from the Atlantic and the Mediterranean feed in the area at this time of year. Conservationists are particularly worried about the Iberian guillemot (Uria aalge ibericus), of which fewer than 20 pairs are known to exist in the area.

Environmental organization the World

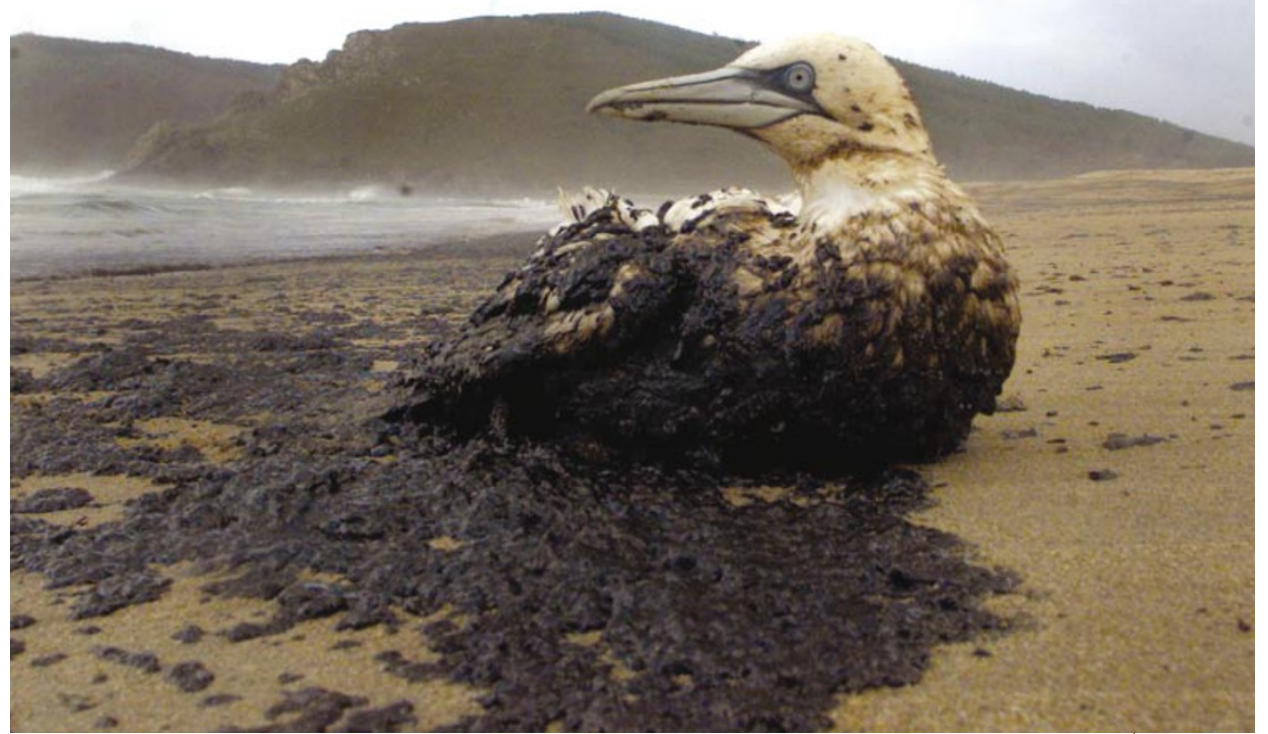

Beached: northwestern Spain is struggling to cope with the effects of oil from the wrecked Prestige.

Wide Fund for Nature (WWF) is also concerned about the spill's potential effect on the Galician Bank, an ecologically rich zone located $200 \mathrm{~km}$ off the Spanish coast. Only a few months ago, the WWF asked for the area to be given special protection.

Urgorri estimates that the region will take at least five years to recover, even if the extra oil remains on the sea floor. $\mathrm{He}$ and colleagues have studied the impact of the 1992 spill, which came from the Aegean Sea tanker. "Most of the species affected at the time have more or less recovered, but they needed a decade," he says.

This spill has spread over a much larger area, although the covering of oil is thinner, which could speed up recovery. "The less affected areas will act as reservoirs for species," says Ricardo Prego, head of the marine biogeochemistry group at the Institute for Marine Studies in Vigo.

The Spanish government is using mechanical cleaning methods, such as removing oil-covered sand from beaches and using high-pressure water jets to clean rocks. But the fuel contains over twice the normal level of sulphur, which is toxic and makes the waste difficult to handle. It is also very dense, and so evaporates more slowly than oil from other spills.

Debate over the government's handling of the disaster is likely to last at least as long as the clean-up operation. Spain's northwestern coast has suffered six major spills in the past three decades. Yet environmental organizations and marine scientists say that the authorities do not have enough cleaning equipment and ships to tackle the latest spill. Critics also allege that the government has deliberately underestimated the amount of oil that has been washed ashore.

As the argument rumbles on, Núñez is keeping his aquarium open. "It is the only place where we can show to the world the dying ecosystem," he says. 